\title{
AUTOMATIC GENERATION CONTROL OF TWO AREA REHEAT THERMAL SYSTEM WITH GENERATION RATE CONSTRAINTS USING FUZZY LOGIC
}

\author{
Jasmendra Singh ${ }^{1}$, H P Tiwari ${ }^{2}$ \\ ${ }^{1}$ M.Tech (Power System), Department of EE, MNIT Jaipur, India \\ ${ }^{2}$ Associate Professor, Department of EE, MNIT Jaipur, India
}

\begin{abstract}
In this paper automatic generation control (AGC) of two area power system has been studied with and without generation rate constraints (GRC). When GRC is introduced in the system then actual frequency deviation is obtained which is more than without GRC consideration case. During load disturbance system frequency goes down which comes back around nominal system frequency on increasing the generation of the system. Overshoot and settling time of frequency deviation increases when GRC is taken into account. Analysis is based on MATLAB/SIMULINK 2010a.
\end{abstract}

Keywords: Fuzzy (FZ), Fuzzy-PI (FZPI), Proportional-Integral (PI) Controller

\section{INTRODUCTION}

In any power system there should be balance between power supply and power consumption in order to provide electricity with reliability and good quality. Whenever there is any load disturbance on the system, frequency deviation takes place. When frequency goes down then generation needs to be increased. Increase in real power generation will increase the system frequency [2]. Generation on any system can not be changed suddenly. There is some restriction on the rate of change of generation, known as generation rate constrains (GRC) [6]. For sudden increase in generation steam flow is to be changed suddenly which will increase the temperature of the turbine which is towards inflow and the temperature of other part will be at its initial value. Hence, high temperature difference can damage the turbine [5]. So, GRC should be considered while designing any system. There is restriction on the increment of generation and decrement of generation due to these generation rate constraints. For thermal plants standard value of GRC is given $3 \% / \mathrm{min}$ which means $0.0005 \mathrm{puMW} / \mathrm{sec}$ [6]. In this paper, study of two area reheat thermal system is done for both cases -with and without GRC with different controllers. Proportional-Integral controller (PI) comes under conventional controller and it gives much transients as compare to fuzzy inference system based techniques.
Frequency deviation analysis is done with PI, fuzzy and fuzzy-PI controllers for both the areas for a given step load disturbance in area-1. Frequency deviation analysis is done for both the areas in terms of overshoot, settling time and steady state error. Frequency deviation in the system mainly depends on real power variation. Therefore, real power is to be increased whenever frequency goes down [2]. If generation dominates consumption then frequency rises and vice-versa. There are some reasons why system should be operated around nominal frequency such as-performance of 3-phase AC motors will be affected as speed of these motors directly depends on frequency and saturation problem in power transformers during under frequency operation in constant voltage mode operation [10]. Turbine blades are specified for the frequency range [47.5 52.5] Hz. Beyond this limit blades can be damaged.

\section{SYSTEM MODEL}

Two area reheat thermal system has been studied here for both with and without GRC cases for a step load disturbance of $0.1 \mathrm{pu}$ in area-1. Here tie-line power acts as an additional disturbance to any area. Block diagram of two area reheat thermal system is shown in Fig.1. 


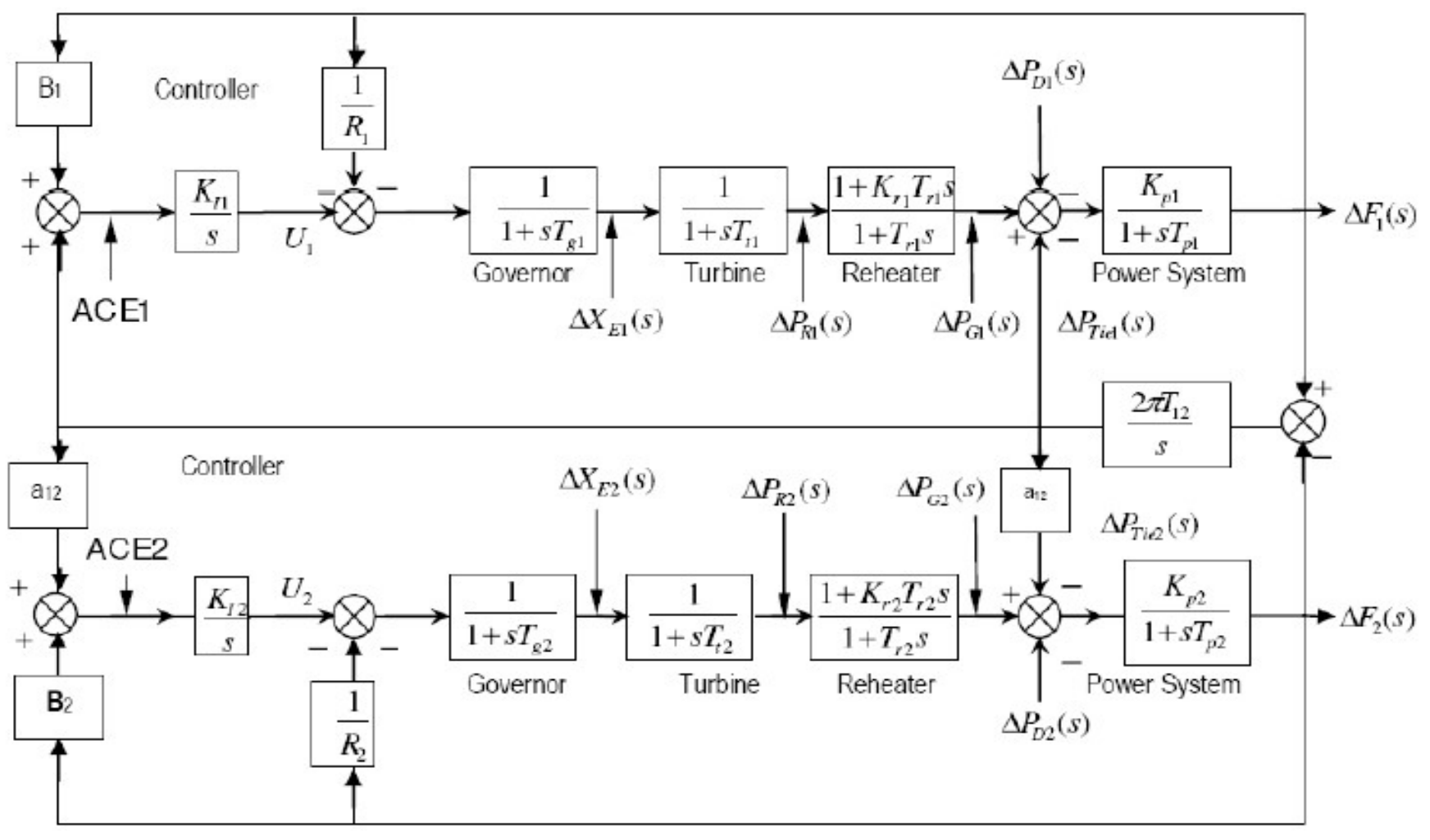

Fig.1: Block diagram of two area reheat thermal system [6]

\subsection{System Modeling with GRC}

In thermal plants, rate of change of power generation can be varied only at given maximum rate [6]. Limiters are introduced with governors for the restriction of generation rate for these plants. Governor with limiter is shown in Fig. 2 .

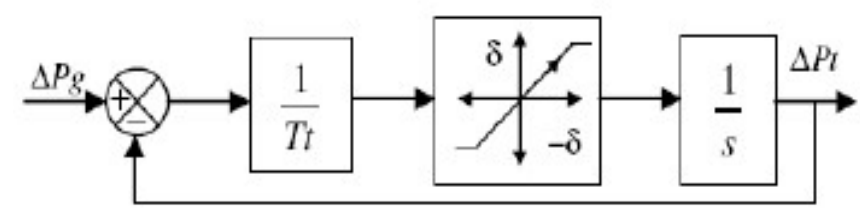

Fig.2: Non-linear turbine model with GRC [6]

\section{INTEGRAL CONTROL}

It consists of a frequency sensor and an integrator. Area control error is given as input to the integrator. The integrator of each area provides the required real power command signal $\left(\Delta \mathrm{P}_{\mathrm{C} 1}, \Delta \mathrm{P}_{\mathrm{C} 2}\right)$ which are given by-

$$
\begin{aligned}
& \Delta \mathrm{P}_{\mathrm{C} 1}=-\mathrm{K}_{\mathrm{i} 1} \int\left(\mathrm{ACE}_{1}\right) \mathrm{dt} \\
& \Delta \mathrm{P}_{\mathrm{C} 2}=-\mathrm{K}_{\mathrm{i} 2} \int\left(\mathrm{ACE}_{2}\right) \mathrm{dt}
\end{aligned}
$$

Where, $\Delta \mathrm{P}_{\mathrm{C} 1}$ and $\Delta \mathrm{P}_{\mathrm{C} 2}$ are inputs of speed changers in area-1 and area- 2 respectively, $K_{i 1}$ and $K_{i 2}$ are integral gains of area- 1 and area- 2 respectively.

$\mathrm{K}_{\text {crit }}=(1 / 4) \mathrm{T}_{\mathrm{ps}} \mathrm{K}_{\mathrm{ps}}\left(1+\mathrm{K}_{\mathrm{ps}} / \mathrm{R}\right)^{2}=$ critical value of gain
For damped and non-oscillatory response gain value should be less than its critical value [3].

\section{FUZZY INFERENCE SYSTEM}

On the basis of fuzzy rule base, fuzzy inference system (FIS) gives mapping of input space to the output space. Degree of membership lies between 0 and 1 [7]. Here each of the input and output variable consists of 5 membership functions. Hence, total 25 rules are implemented using "if-then" rules. The FIS consists of following main components-

1. Fuzzyfier: It converts numerical values of inputs into linguistic variables. This process is known as fuzzification. $\mathrm{ACE}$ and its derivative $(\mathrm{d}(\mathrm{ACE}) / \mathrm{dt})$ are inputs to the fuzzy system [6]. Five linguistic variables for each of the input and output variable are used here to describe them. Linguistic variables are-Negative Big (NB), Negative Small (NS), Zero (ZR), Positive Small (PS) and Positive Big (PB).

2. Rule Base and Inference Engine: The way in which rules are applied- if input 1 is NB and input 2 is PB then output 1 is ZR. The 'if' part of the rule means "rule-antecedent" and 'then' part means "rule-consequent" [6]. Mapping from input fuzzy sets into output fuzzy sets is defined by inference engine. The degree of satisfaction of antecedent for each rule is also determined by it.

3. Defuzzification: In this process linguistic variable is converted into crisp output or real number. Centre of gravity method of defuzzification has been used here in Mamdani-type fuzzy system with 25 rules. Fig. 4 gives the specification of Mamdani-type fuzzy system with two inputs and one output. 


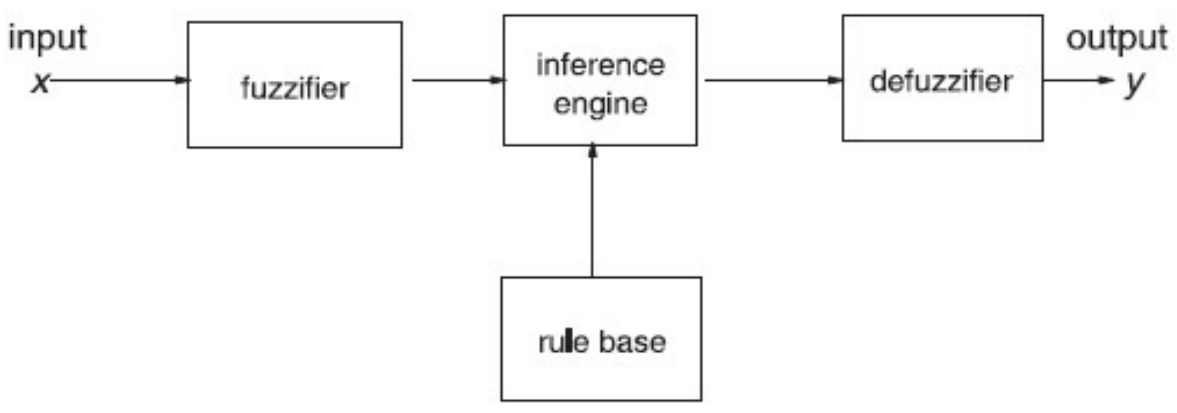

Fig.3: Fuzzy inference system block diagram

Table 1: Fuzzy Rules

\begin{tabular}{|c|c|c|c|c|c|c|}
\hline & \multicolumn{5}{|c|}{ input $2(\mathrm{~d}(\mathrm{ACE}) / \mathrm{dt})$} \\
\hline & & NB & NS & $\mathrm{Zl}$ & PS & PB \\
\hline \multirow{5}{*}{$\begin{array}{l}\text { input1 } \\
\text { (ACE) }\end{array}$} & NB & NB & NB & NB & NS & ZR \\
\hline & NS & NB & NB & NS & ZR & PS \\
\hline & ZR & NB & NS & ZR & PS & PB \\
\hline & PS & NS & ZR & PS & PB & PB \\
\hline & PB & ZR & PS & PB & PB & PB \\
\hline
\end{tabular}

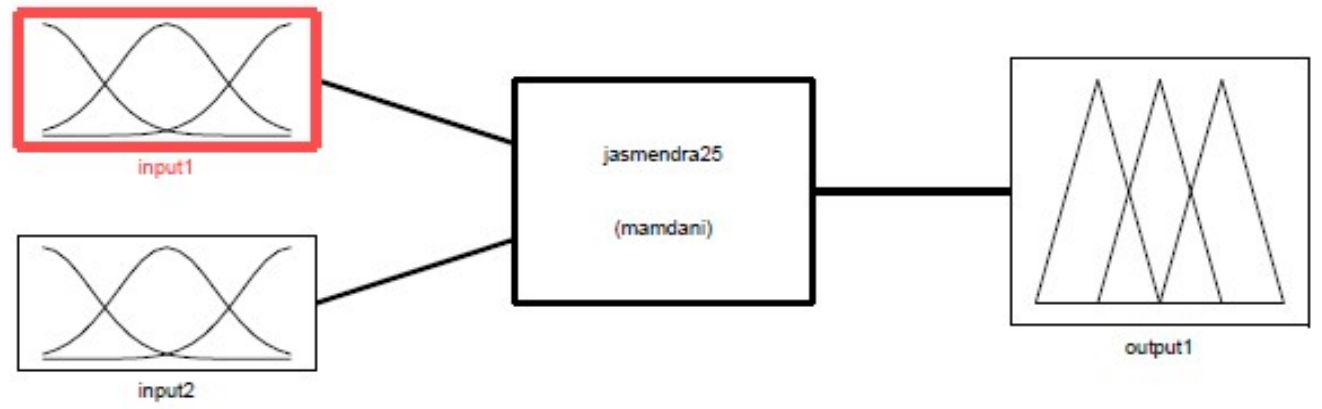

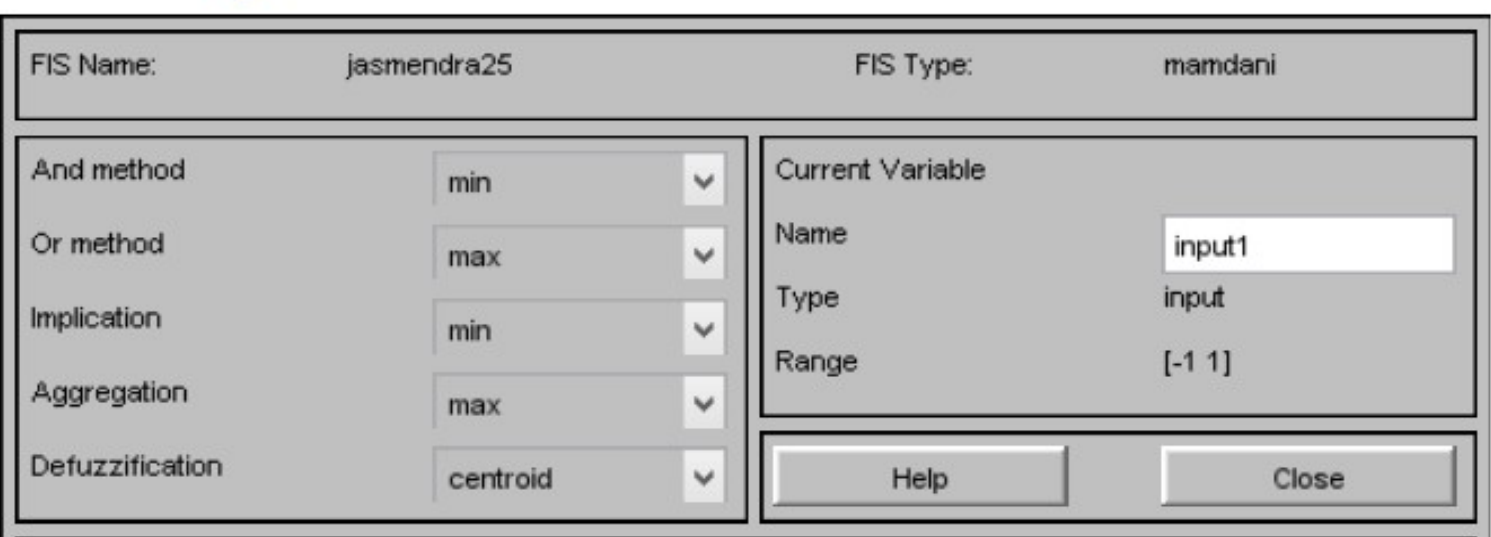

System "jasmendra25": 2 inputs, 1 output, and 25 rules

Fig.4: FIS Editor with Two Inputs and Single Output

We have used triangular membership functions for both the inputs and the output in the designing of fuzzy controller. Centroid method of defuzzification has been used for defuzzification process. Designing of fuzzy is shown in Figures from Fig.4 to Fig.9. 


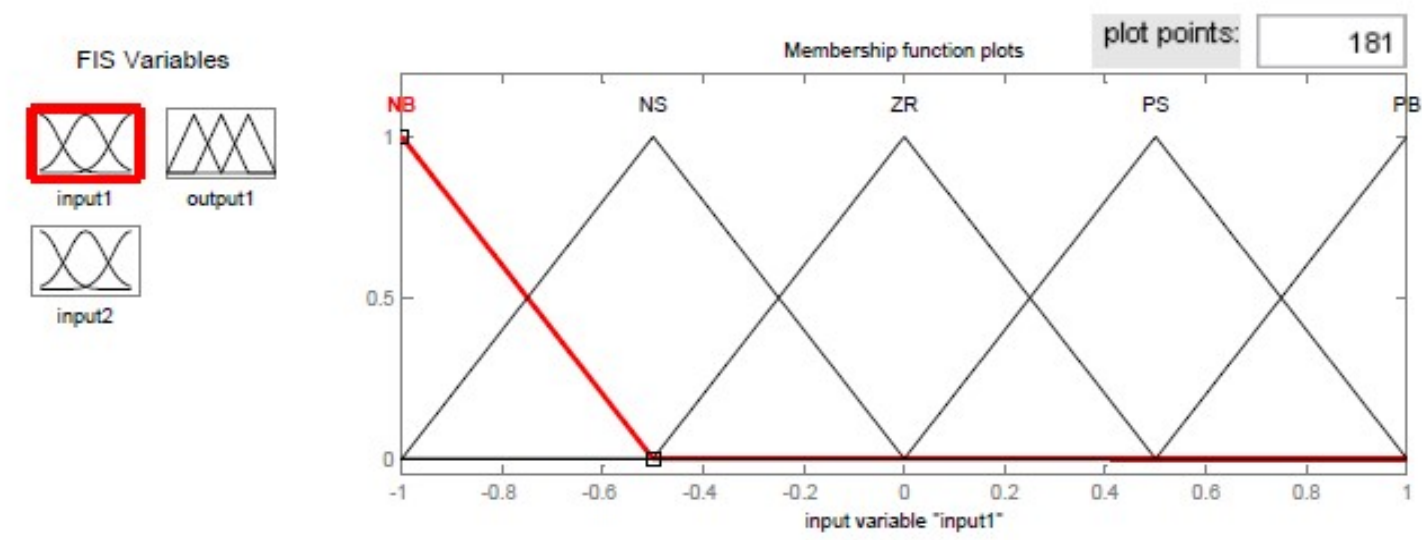

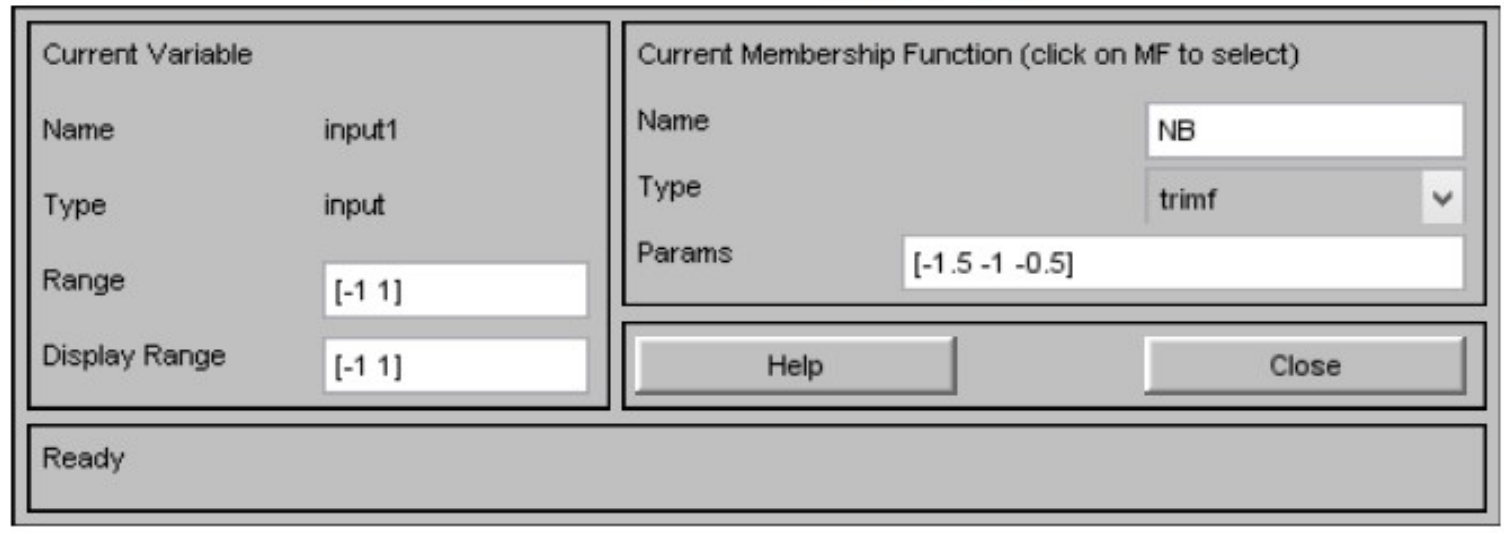

Fig.5: Input1 with Membership Functions

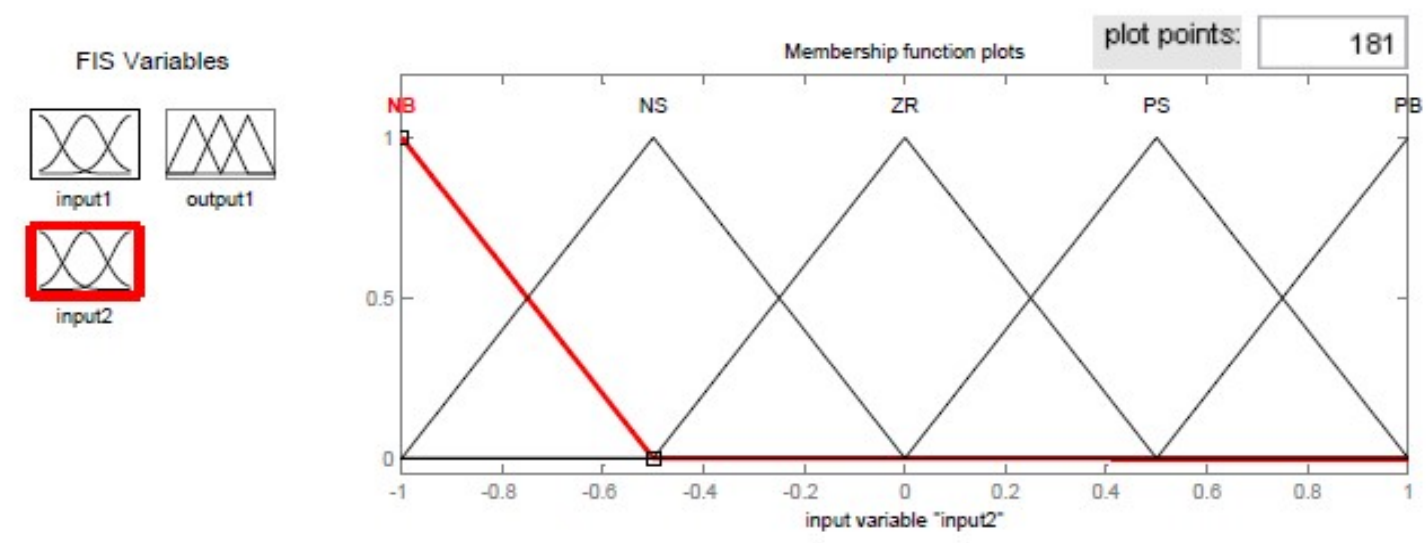

\begin{tabular}{|c|c|c|c|c|c|}
\hline Current Variabl & & \multicolumn{4}{|c|}{ Current Membership Function (click on MF to select) } \\
\hline Name & input2 & \multirow{3}{*}{$\begin{array}{l}\text { Name } \\
\text { Type } \\
\text { Params }\end{array}$} & & \multicolumn{2}{|l|}{ NB } \\
\hline Type & input & & & trimf & $\checkmark$ \\
\hline Range & {$\left[\begin{array}{ll}-1 & 1\end{array}\right]$} & & \multicolumn{3}{|l|}{$\left[\begin{array}{lll}-1.5 & -1 & -0.5\end{array}\right]$} \\
\hline Display Range & {$[-11]$} & \multicolumn{2}{|l|}{ Help } & \multicolumn{2}{|l|}{ Close } \\
\hline
\end{tabular}

Fig.6: Input 2 with Membership Functions 


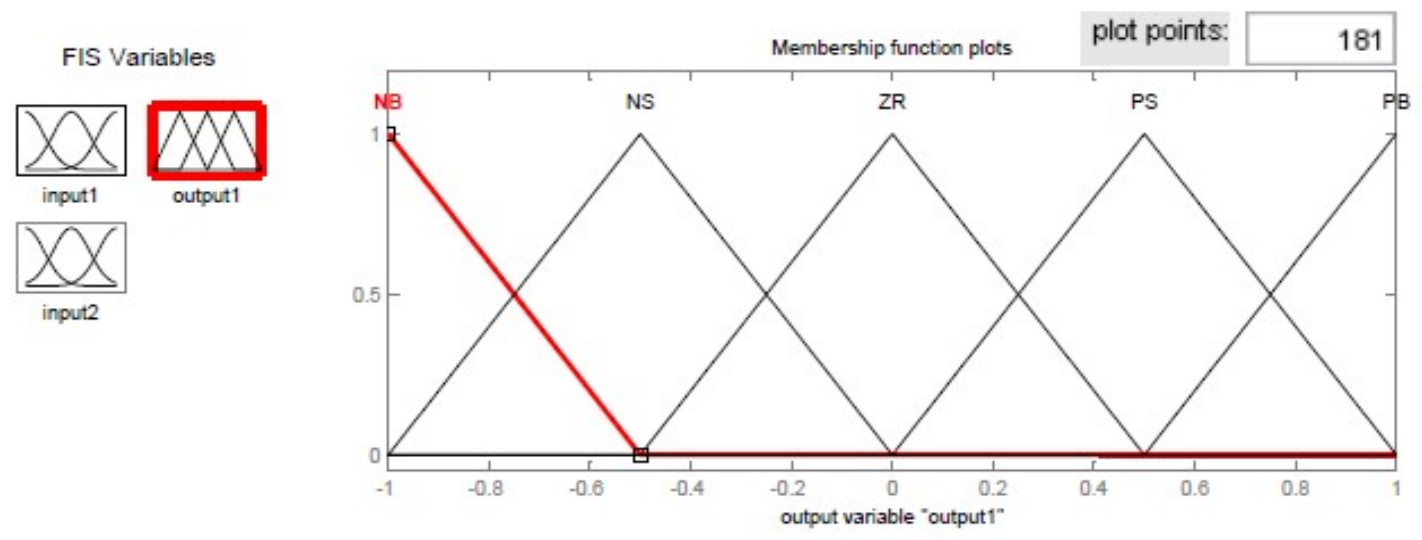

\begin{tabular}{|c|c|c|c|c|c|}
\hline Current Variab & & \multicolumn{4}{|c|}{ Current Membership Function (click on MF to select) } \\
\hline Name & output1 & \multirow{3}{*}{$\begin{array}{l}\text { Name } \\
\text { Type } \\
\text { Params }\end{array}$} & & \multicolumn{2}{|l|}{ NB } \\
\hline Type & output & & & trimf & $\checkmark$ \\
\hline Range & {$\left[\begin{array}{ll}-1 & 1\end{array}\right]$} & & \multicolumn{3}{|l|}{$\left[\begin{array}{lll}-1.5 & -1 & -0.5\end{array}\right]$} \\
\hline Display Range & {$[-11]$} & Help & & \multicolumn{2}{|l|}{ Close } \\
\hline
\end{tabular}

Fig.7: Output with Membership Functions

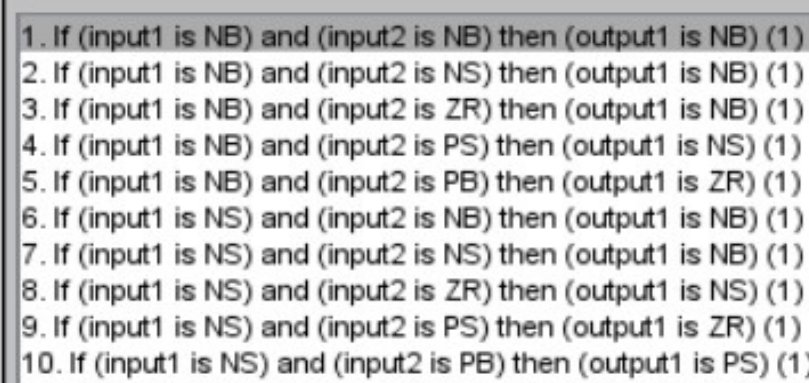

10. If (input1 is NS) and (input2 is PB) then (output1 is PS) (1)

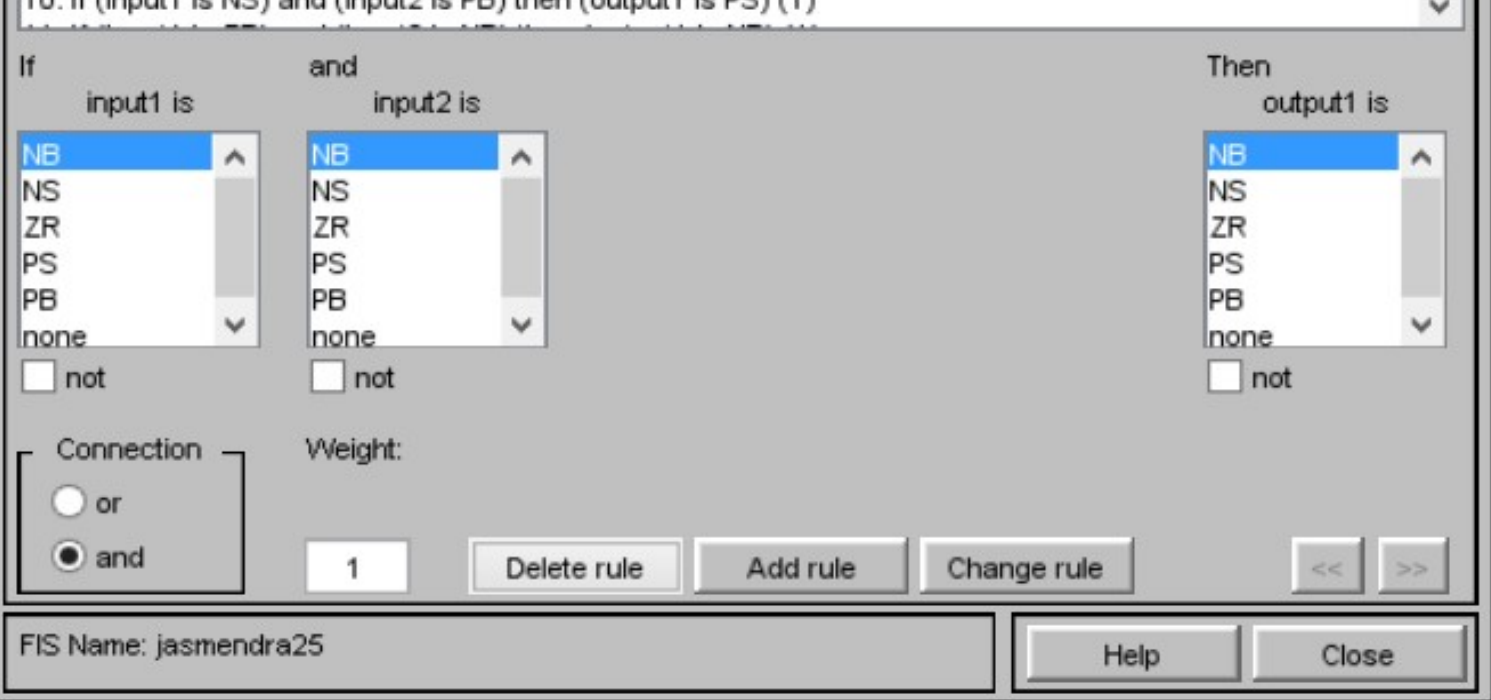

Fig.8: View of Edit Rules with the Applied Rules 


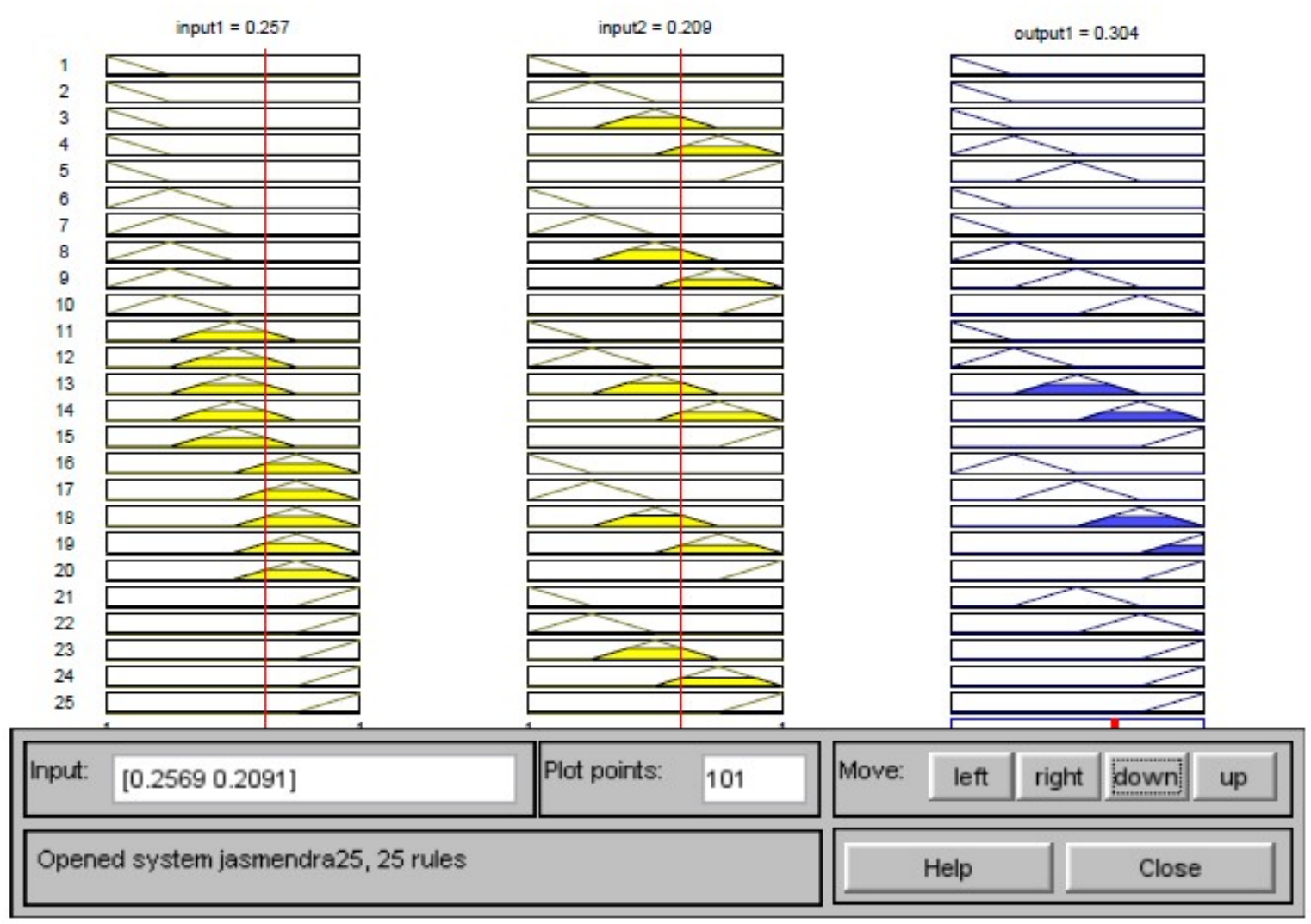

Fig.9: View of Rules for a Set of Inputs with Corresponding Output

\section{SIMULATION \& RESULTS}

Simulation model for two area reheat thermal system with fuzzy controller is shown in Fig.10 and with fuzzy-PI is shown in Fig.11. For a step load disturbance of $0.1 \mathrm{pu}$ in area-1, these results were obtained. Table 2 shows the frequency deviation analysis of area- 1 and area- 2 . System is studied here- 1. With PI Controller 2. With Fuzzy (FZ) 3. With Fuzzy-PI (FZPI) Controller

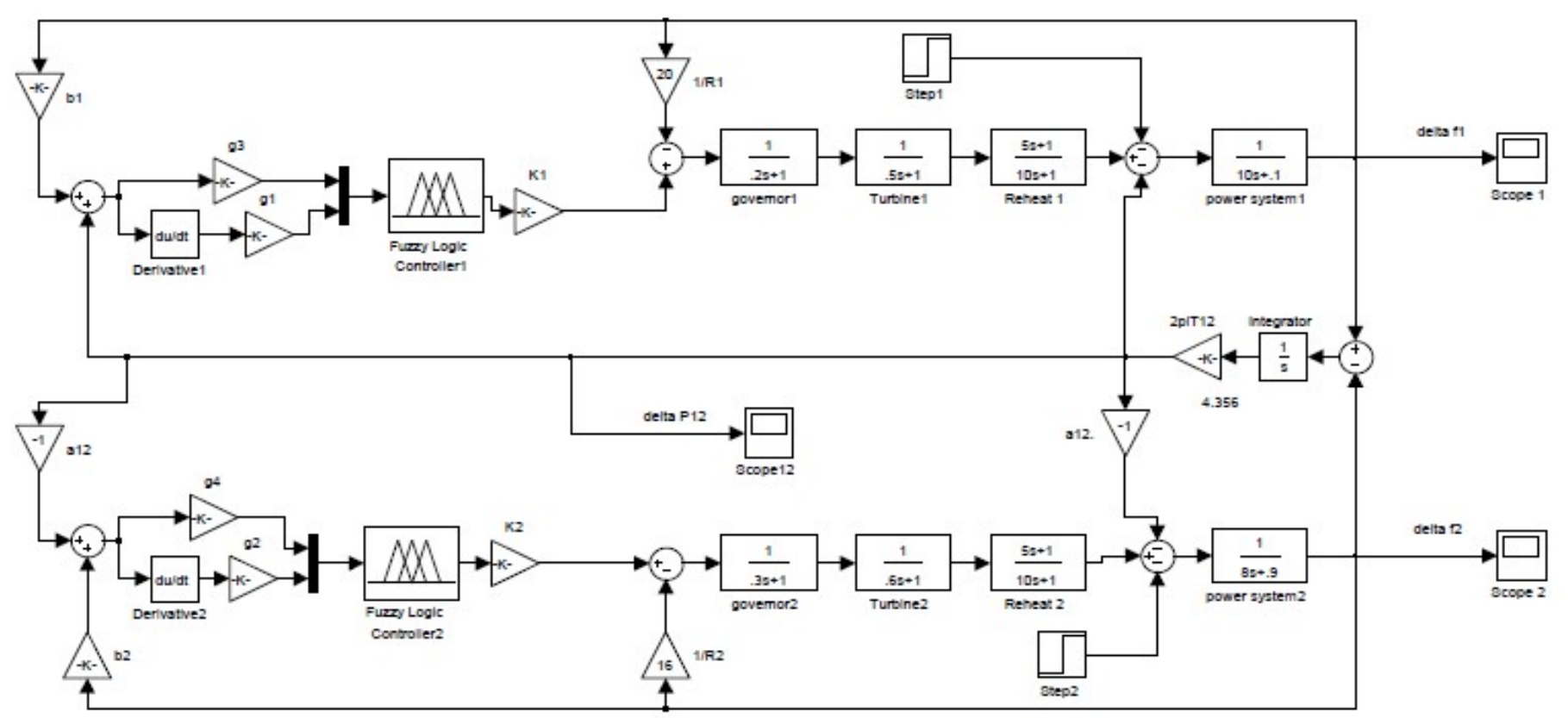

Fig.10: Simulation Model for Two Area LFC with Fuzzy 


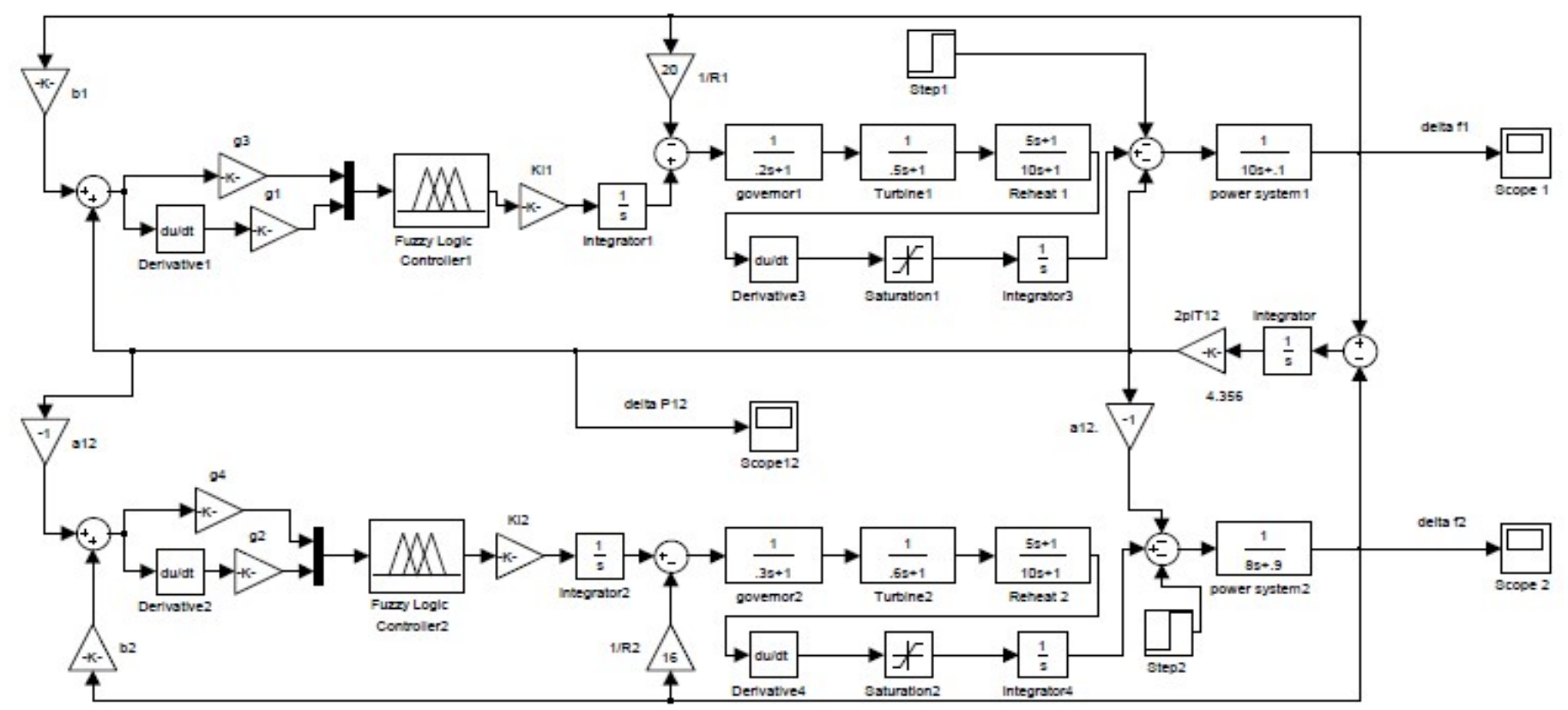

Fig.11: Simulation model of two-area reheat thermal system with FZPI

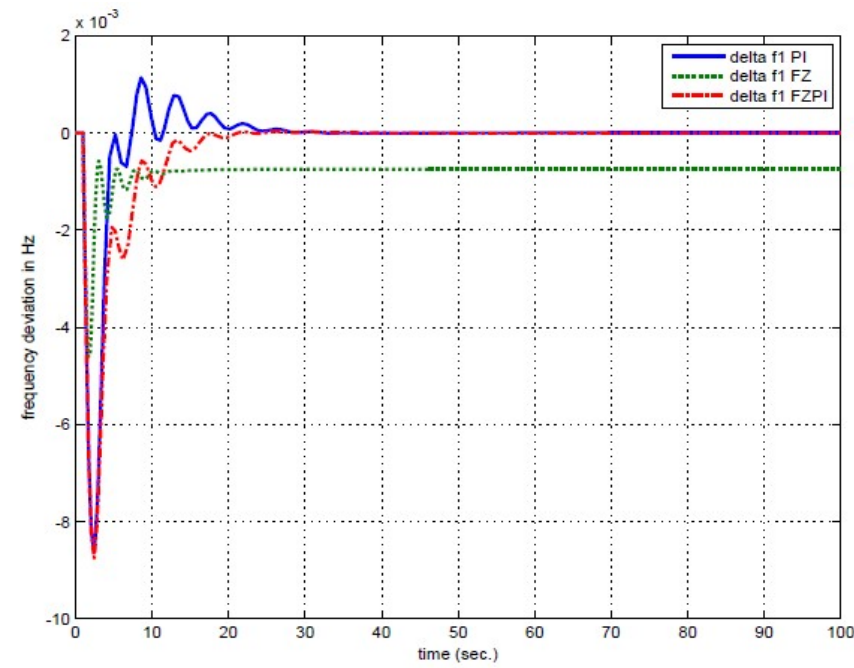

Fig.12: Frequency deviation of area-1 without GRC

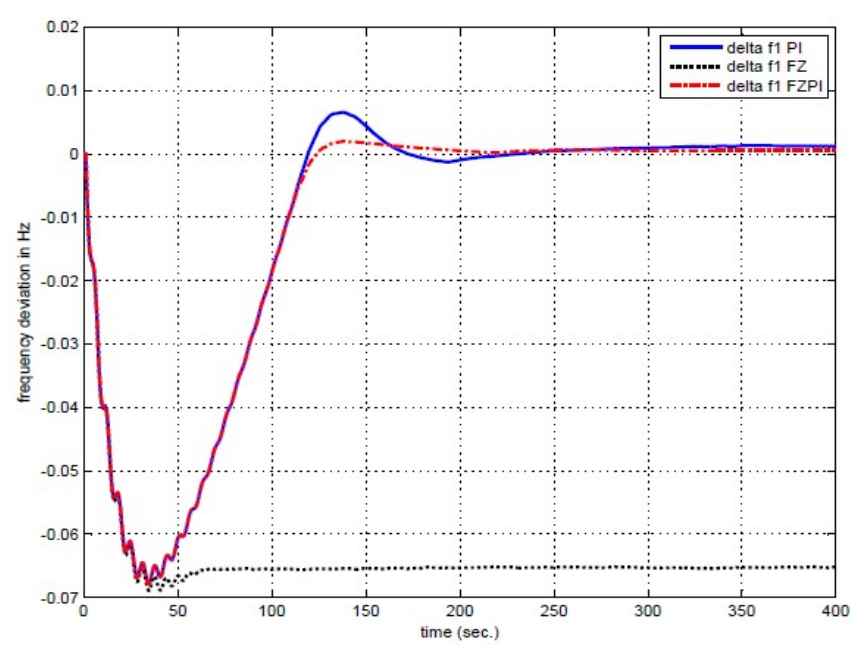

Fig.13: Frequency deviation of area-1 considering GRC

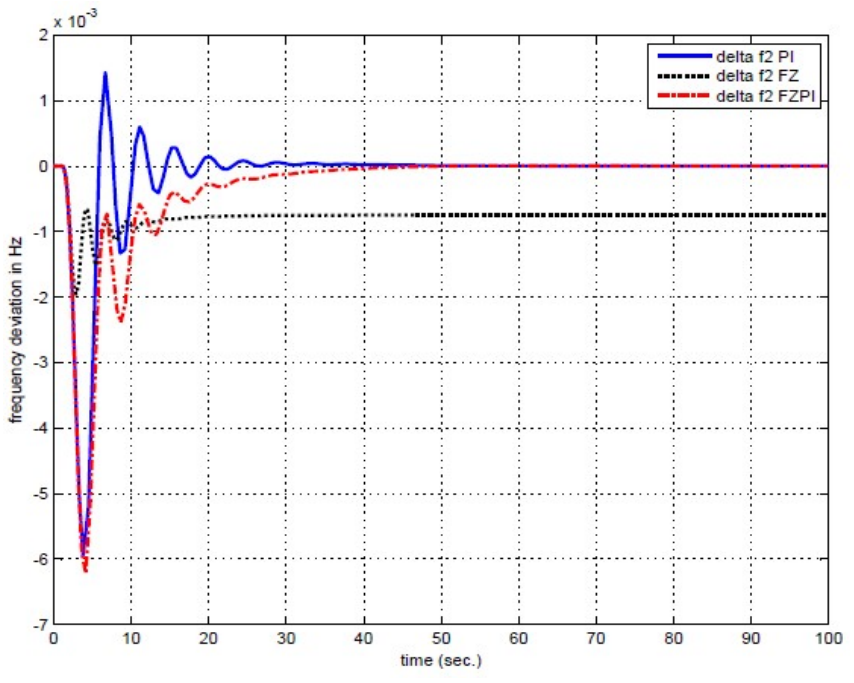

Fig.14: Frequency deviation of area-2 without GRC

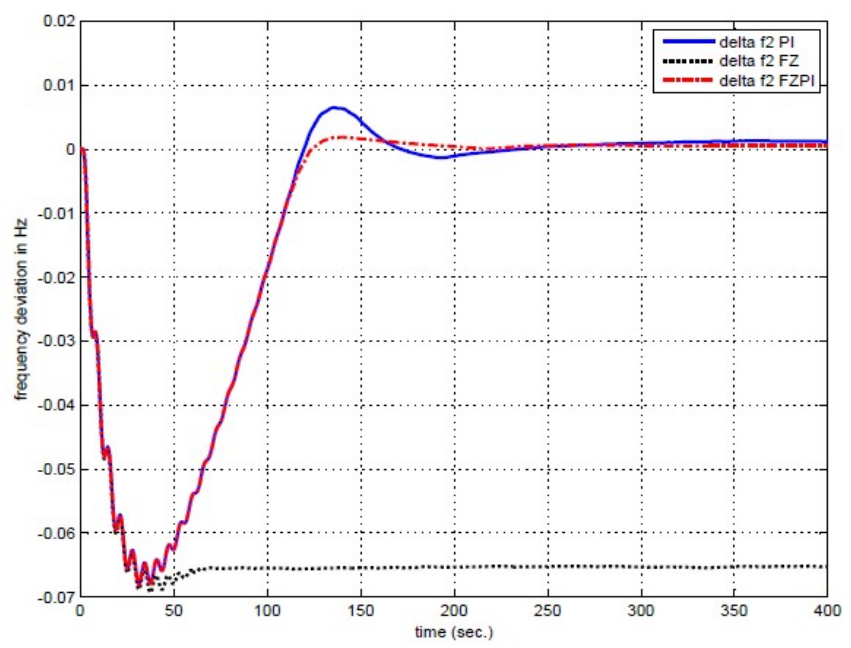

Fig.15: Frequency deviation of area-2 with GRC 
Fig.14 shows the frequency deviation of area-2 with the proposed controllers when GRC is not considered and Fig. 15 shows this deviation when GRC is considered.

Fig.16 gives the tie-line power deviation for the system with the given controllers when GRC is not taken into account and Fig. 17 shows this deviation when GRC is taken into account.

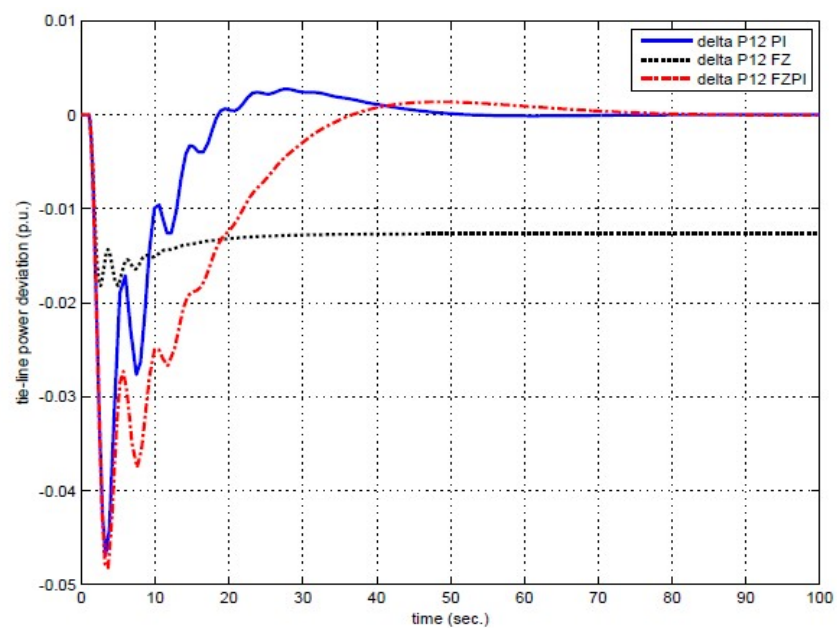

Fig.16: Tie-line power deviation without GRC

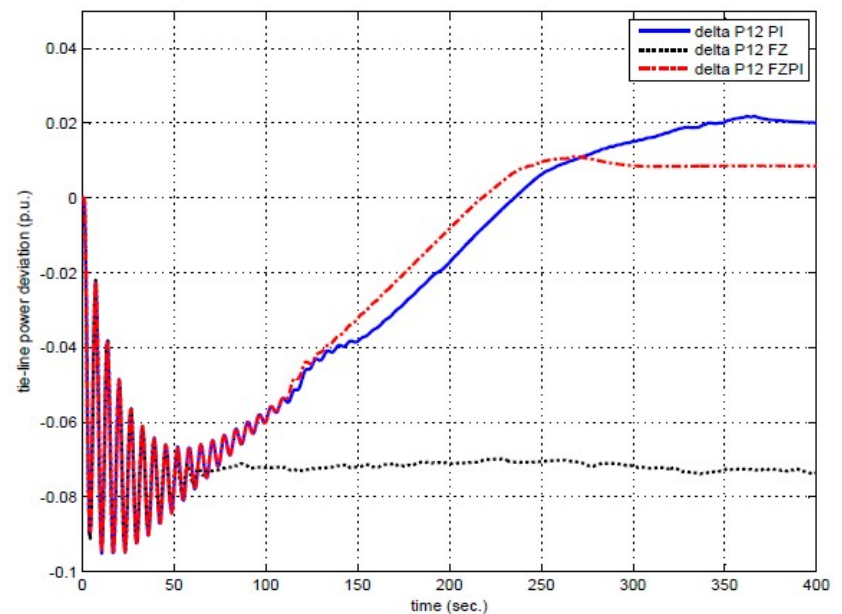

Fig.17: Tie-line power deviation with GRC

\section{CONCLUSION}

In this study, performance of PI, fuzzy and fuzzy-PI is compared for frequency deviation analysis with and without GRC for area-1 and area-2 in terms of overshoot, settling time and steady state error. Fuzzy controllers handle nonlinearity in a better way as compare to conventional controllers. Analysis is given below in Table 2 .

Table 2: Frequency deviation analysis for area-1 and area-2

\begin{tabular}{|l|l|l|l|l|l|l|}
\hline Parameter for $\Delta \mathrm{f}_{1}$ & FZ & FZ-GRC & PI & PI-GRC & FZPI & FZPI-GRC \\
\hline Overshoot $(\mathrm{Hz})$ & -0.00465 & -0.069 & -0.0086 & -0.068 & -0.0087 & -0.068 \\
\hline Settling time(sec) & 12 & 70 & 28 & 240 & 22 & 210 \\
\hline Steady state error(Hz) & -0.00075 & -0.066 & 0 & 0.002 & 0 & 0.001 \\
\hline Parameter for $\Delta \mathrm{f}_{2}$ & & & & & & \\
\hline Overshoot $(\mathrm{Hz})$ & -0.00195 & -0.069 & -0.006 & -0.068 & -0.0062 & -0.068 \\
\hline Settling time(sec) & 20 & 65 & 50 & 240 & 45 & 210 \\
\hline Steady state error(Hz) & -0.00075 & -0.066 & 0 & 0.002 & 0 & 0.001 \\
\hline
\end{tabular}

\section{APPENDIX}

The nominal system parameters are: $\mathrm{f}=50 \mathrm{~Hz}$, $\mathrm{T}_{\mathrm{g} 1}=0.2 \mathrm{~s}, \quad \mathrm{~T}_{\mathrm{g} 2}=0.3 \mathrm{~s}, \quad \mathrm{~T}_{\mathrm{t} 1}=0.5 \mathrm{~s}, \quad \mathrm{~T}_{\mathrm{t} 2}=0.6 \mathrm{~s}, \quad \mathrm{~T}_{\mathrm{r} 1}=\mathrm{T}_{\mathrm{r} 2}=10 \mathrm{~s}$, $\mathrm{K}_{\mathrm{r} 1}=\mathrm{K}_{\mathrm{r} 2}=0.5, \quad \mathrm{H}_{1}=5 \mathrm{MW}-\mathrm{sec} / \mathrm{MVA}, \quad \mathrm{H}_{2}=4 \mathrm{MW}-$ sec/MVA, $\quad 1 / \mathrm{R}_{1}=20 \mathrm{puMW} / \mathrm{Hz}, \quad 1 / \mathrm{R}_{2}=16 \mathrm{puMW} / \mathrm{Hz}$, $\mathrm{b}_{1}=20.1 \mathrm{puMW} / \mathrm{Hz}, \mathrm{b}_{2}=16.9 \mathrm{puMW} / \mathrm{Hz}, 2 \Pi \mathrm{T}_{12}=4.356$, $\mathrm{a}_{12}=-1$

\section{REFERENCES}

[1] Haadi Sadat, "Power System Analysis", McGraw-Hill companies Inc. 1999.

[2] J Nagrath and D P Kothari, "Modern Power System Analysis", $4^{\text {th }}$ Edition.

[3] Nilaykumar N Shah, Dwij N Mehta, Aditya D Chafekar, Anant R Suthar, "Automatic Load Frequency Control of Two Area Power System with Conventional and Fuzzy Logic Control", International Journal of
Research in Engineering and Technology, vol. 01, pp. 343-347, 2012.

[4] Atul Ikhe, Anant Kulkarni, Dr. Veeresh, "Load Frequency Control using Fuzzy Logic Controller of Two Area thermal-thermal Power System", International Journal of Emerging Technology and Advanced Engineering, vol. 2, pp. 425-428, 2012.

[5] Naresh Kumari, A N Jha, "Effect of Generation Rate Constraint on Load Frequency Control of Multi-Area Interconnected thermal Systems", Journal of Electrical and Electronics Engineering Research, vol. 5(3), pp. 4449, 2013.

[6] Gayadhar Panda, Sidhartha Panda, Cemal Ardil, "Automatic Generation Control of Interconnected Power System with Generation Rate Constraints by Hybrid Neuro Fuzzy Approach", World Academy of Science, Engineering and Technology, pp. 543-548, 2009. 
[7] Siraparapu Satyanarayana, R K Sharma, Gaur Mukta, Sappa Anil Kumar, "Automatic Generation Control in Power Plant using PID, PSS and Fuzzy-PID Controller", IEEE 2014.

[8] Surya Prakash, S K Sinha, “Artificial Intelligent \& PI in Load Frequency Control of Interconnected Power System", International Journal of Computer Science \& Emerging Technologies", vol.1, pp.377-384, 2010.

[9] Roohi Kansal, Balwinder Singh Surjan, "Study of Load Frequency Control in an Interconnected System using Conventional and Fuzzy Logic Controller", International Journal of Science and Research, vol. 3, pp.728-734, 2014.

[10] Prem Kumar, Mr. BSSPM Sharma, "Design and Simulation of Integral Controller Based LFC", ISORJournal of Electrical and Electronics Engineering, vol. 10, pp. 98-105, 2015.

\section{BIOGRAPHY}

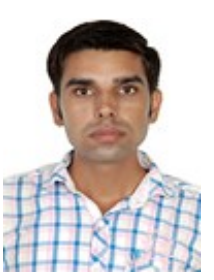

Jasmendra Singh is State Topper in Rajasthan Board in Hindi Medium School Life. He obtained $87.83 \%$ in Class $10^{\text {th }}$ (2005, Science-96, Eng. 94, Maths-91) and in Class $12^{\text {th }} 86.31 \%$ in 2007 with $90 \%$ in PCM (Physics-131/150, Maths-135/150, Chemistry-138/150, Eng. 86). He is AIR19,159 in AIEEE-2009 (203/432, Eng. Med.). He received his B.Tech degree from NIT Silchar in Electrical Engineering on $12^{\text {th }}$ May 2013. He is AIR-2186 in GATE$2013(51.67 / 100)$ with his B.Tech. He has completed his M.Tech in Power System from MNIT Jaipur in 2016. His Research interest includes Automatic Generation Control, Control System, Power Electronics, FACTS Devices, Digital Signal Processing and AI Techniques. 